\title{
Prospects for the Minerals Industry: A View from a Mining Company
}

\author{
Phillip Crowson
}

For most of the past decade the managements of international mining companies have been predominantly concerned with their corporate survival. They have had to cope with the consequences of excess capacity created by the failure of demand to live up to the extravagant expectations of the 1960s and early 1970 s, and, in more muted form, of the late 1970s. In retrospect demand predictions for all minerals which were in general currency even five years ago now appear too optimistic. Such predictions were shared by mining companies as much as by governments and consumers. Against this background new developments have been far from the thoughts of most mining companies. The keynote of most corporate statements of recent years has been retrenchment and cost reduction in the face of adverse structural change. Opinions may differ over the magnitude of this change, and indeed over whether it is genuinely structural or merely of an extended cyclical nature. Such niceties are not debated in an industry facing adversity. Yet they are by no means irrelevant questions because different answers will dictate differing strategies for the next decade.

\section{The State of Mineral Markets}

Excess capacity has been the most marked and pervasive characteristic of mineral industries in recent years. Table 1 summarises, in a rough and ready form, the world's capacity utilisation in 45 minerals in the mid 1980s.

The table covers all the main metallic and non-metallic minerals entering international trade, and many of lesser importance. The data, with all their underlying statistical and conceptual weaknesses, should not be strained too far. None the less, capacity utilisation exceeds 75 per cent in less than a quarter of the minerals, and many of those are of little economic significance. The four with the highest utilisation rates, for example, are graphite, strontium, gypsum, and silver. More than adequate supplies of the last two are available from sources other than primary mining.
Table l

World Capacity Utilisation in Minerals: Mid 1980s

Production in 1984 as percentage of estimated capacities in 1985

\begin{tabular}{|c|c|c|}
\hline Capacity Utilisation ? & & No. of Minerals \\
\hline Over 80 & & 4 \\
\hline $75-80$ & & 6 \\
\hline $70-75$ & & 6 \\
\hline $65-70$ & & 7 \\
\hline $60-65$ & & 7 \\
\hline $55-60$ & & 7 \\
\hline $50-55$ & & 2 \\
\hline $45-50$ & & 3 \\
\hline \multirow[t]{2}{*}{ Under 45} & & 3 \\
\hline & Total: & 45 \\
\hline
\end{tabular}

Source: Based on US Bureau of Mines' Data (Mineral Facts and Problems, and Mineral Commodity Summaries).

In the short to medium term there is ample capacity to meet present and prospective demand for nearly all minerals, provided prices are right. That would be so even when due allowance is made for strikes and other disruptions, and for the gradual attrition of uneconomic projects.

Arithmetically, it would take five years of five per cent per annum growth, and eight years of three per cent per annum growth for capacity utilisation to rise from 75 to 95 per cent. Not only is capacity well below 75 per cent in most cases, but some limited investment continues in many minerals, and demand has been growing much more slowly than three per cent per annum, even allowing for cyclical variations in growth rates.

IDS Bullein, 1986, vol 17 no 4, Institute of Development Studies, Sussex 
This rudimentary analysis demonstrates that the problem of excess capacity is not confined to those minerals which are most widely traded internationally, nor to those which have received the most publicity. Not all minerals have been affected to the same degree, if at all, by substitution induced by miniaturisation and technical innovation. Nor has the diffusion of ownership apparent in the main metallic minerals in the late 1960 s and early 1970 s been common in many non-metallic minerals or minor metals. In short, each individual mineral's problems have been exacerbated by specific structural influences, but the basic problems were created by the unexpected and prolonged slowdown in the world's economic growth rates.

A major effect of prolonged excess capacity has been to drive prices down below even the variable costs of production of a substantial portion of the world's capacity. Many of the mines and processing facilities consequently forced into losses might be technically efficient and well managed. They probably would have regarded themselves as reasonably well insulated from adverse price fluctuations, which may have been aggravated by unpredictably varying exchange rates. The near universal response of the minerals industry, state as much as privately owned, has been to concentrate single-mindedly upon reducing costs, both for existing operations and for such new ventures as have survived. It is an economic truism, in stagnant or over supplied markets, that the full costs (at an acceptable rate of return on capital) of completely new operations should be no greater than the variable costs of existing plants, if new investment is to be justified. Very few projects can pass this rigorous test after a period of rapid capital cost escalation, and with historically high real costs of debt servicing.

The mining industry, as a whole, has been successful not just in restraining but also in reducing its costs. The average costs of mining and milling per tonne of ore treated have fallen in the United States since 1981 by some 15 to 20 per cent. Elsewhere costs have declined by around 20 to 30 per cent from their peak of the early 1880 s. Outside the United States much of the decline was due to the depreciation of local currencies against the US dollar, but there have also been genuine improvements in efficiency. The effects of the drop in mining costs have been accentuated in many instances by mines raising their cut off grades. These cannot be altered very often, and any change imposes a delayed cost. Indeed a sizeable, but totally unknown proportion of the industry's cost cutting has been purchased through reductions in economically accessible reserves, through the shortening of mine lives, or through the delay of necessary spending. Replacements of equipment may have been delayed, advance development deferred, and maintenance skimped. Exploration expenditure was often one of the first items to be cut.

If much of the response to weak markets has been to defer costs, there has also been a permanent improvement of productivity, in all aspects of mineral production, distribution, and marketing. The belated recognition that prices would not rise to bail out those making losses forced a continuing reassessment of production techniques. The application of computers to all aspects of the industry from exploration onwards, the use of more efficient and safer explosives, the design and introduction of less energy or labour intensive processes, and simplification and decentralisation of management structures are a few of the many avenues that have been explored. As innovations diffuse throughout the industry, there will be further declines in average costs, irrespective of any change in exchange rates or input costs. This means that in real terms mineral prices will probably not recover even to their previous averages.

Switching to demand, the outlook depends primarily on the growth of economic activity, especially in newly industrialising and developing countries. There has been considerable debate within the mining industry about the extent to which minerals are going out of fashion. The concern has been most intense in the older base metals such as copper. The threats from substitution are here most immediately obvious, as indeed they have been for the last 30 years. The statistical evidence in fact shows that there has been no sudden change in the relationship between the growth of demand for metals, including copper, and the growth of economic activity, however it is defined. The consumption of copper, lead, and tin per unit of GDP measured in real terms for the Western World as a whole has declined at fairly constant rates throughout the post-war period. The rate of decline of zinc consumption per unit of GDP accelerated from 1969-70 onwards and there was a change in trend for aluminium and nickel in the mid 1970s. In other words, there has, in most instances, been no dramatic new factor affecting the consumption of metals during the past few years.

Metals have admittedly suffered from the reducing share of GDP devoted to capital expenditure of all types. The main cause of the low growth rates of demand for metals has, however, been the low growt h rate of the world economy as a whole when compared with the decade up to 1974.

The prospects for the world economy are outside the scope of this article. It is sufficient to note the general belief that the next decade's growth rates will be no worse than those of the last decade, and possibly much better. The recent weakening of oil prices and falls in 
interest rates will not make a summer, and the former has been too sudden to be sustainable in the longer run. None the less, these changes have helped lift the clouds which have for so long obscured future economic growth. In the next economic upswing, if not in the next year or so, construction activity and demand for capital will probably revive. Much of the existing capital stock will then be approaching 20 years old, and in many instances much older. The revival of industrial profitability in the present cycle will help provide funds to finance re-equipment, the replacement of degraded and out moded inf rast ructure, and the development of the social capital of those countries where it is presently deficient. There is, therefore, a reasonable prospect that demand for minerals in general, and for the main metallic minerals in particular, will grow rather faster during the 1990s than in the present decade.

Even ignoring this latter prospect, the gradual rise in demand, coupled with the attrition of existing mines and processing facilities, will continue to eliminate excess capacity as the 1990 s unfold. The rate of movement back towards a more healthy balance between demand and capability to supply will vary from one mineral to another. It will also naturally be affected by developments in the economy at large. When balance is regained, however, prices will move back towards a closer relationship with the marginal costs of production than has prevailed for the past 12 years. The improvements in costs, already described, mean that any consequent rise in prices may well be muted. The nature of most mineral markets is such, however, that prices will probably overshoot their equilibrium levels, thereby starting off the cyclical process once again.

\section{Mining Companies' Responses}

Many of those mining companies which have remained in business either with their original capital structures and shareholdings intact, or after being absorbed into other groupings, have a jaundiced view of the mining industry's future. Whilst some might acknowledge the economic logic of the outlook sketched above, they are generally unwilling to commit themselves to new projects. Others would question whether excess capacity will ever be eliminated sufficiently to allow prices to harden.

The international mining companies' expertise may lie in the discovery, development and management of mines, sometimes in specific products. With a very few exceptions, however, they are not in business to obtain supplies of minerals either for their home countries' consumers or for integrated supply systems. Their main objective is to earn profits for their shareholders. Thus they are not indissolubly wedded to the mining industry. Their alternatives to investing in a specific project are not just investment in other less attractive deposits elsewhere, but also to switch to different areas of business or not invest at all. Diversification away from mining has been a common response to the industry's prolonged recession. Even where companies remain in mining, they have sought to broaden their portfolios, both geographically and by product. In some instances the diversifications have been ill judged, and fingers have been burnt. The differences of a new venture from mining have not been fully appreciated, or the price paid has been too great relative to the prospective return. Periodic failures have not, however, reduced the general desire to broaden asset bases, an objective likely to persist for some years.

Diversification will be accompanied by a continuing quest for lower costs at established operations. It is sometimes forgotten that it is arithmetically impossible for every producer to achieve costs that are in the industry's lowest quartile, but every producer has such an objective. The more others achieve worthwhile cost savings, the greater the pressures on the remainder. This pressure spills over into the consideration of new projects. Regardless of where they are situated, new projects have to compete in world markets throughout their prospective lives. The past decade has amply demonstrated how relative costs can be changed overnight by movements in exchange rates, byproduct credits, or energy prices. There is no assurance that any given ratio or level of factor costs is likely to persist. Hence it is insufficient to rely on relatively low labour or energy costs alone as justification for a project. Even less faith can be placed in investment incentives or favourable tax treatment alone, although both may be needed. Project managers have to aim for internationally competitive costs from the outset and be able to sustain their competitiveness.

Whilst the long established mining companies are in the main drawing in their horns, relative newcomers to the industry are more adventurous. Not only are they often free of the traumas of recent years, but they are able to acquire assets relatively cheaply. Often these assets are sold without any debilitating financing charges and their operating costs are competitive. Unfortunately for market balance, they can produce cheaply, if only for a limited period. As such newcomers acquire experience, they may become interested in totally new projects rather than reopening existing facilities, but it is too soon to tell.

Even those relatively few companies which are interested in developing new mines have become highly selective. The tendency is to go for the higher grade, more accessible deposits. Not only do they 
concentrate on the lower cost projects, but they also expect stable and equitable terms and conditions for their investments. Their caution is accentuated by that of the banks and other financial institutions. Most of these are more sophisticated than the (genuine) bank which believes that today's price escalating at one per cent per annum in money terms is a rational basis for evaluating a copper project. Even so, banks do have a naturally cautious view of the mining industry. Access to adequate loan finance on acceptable terms is invariably a precondition of a mining company's investment. Hence the mining companies have to carry the lenders with them when they contemplate new investments of any magnitude. Recent history has made the banks somewhat chary of lending to large projects in politically or economically unstable areas.

Their caution in turn reinforces that of many mining companies. In consequence, few new projects are under development throughout the mining industry. Many of those which are proceeding are financed by successful state enterprises, such as CODELCO of Chile, are expansions of existing operations, or are so potentially attractive as to surmount the various hurdles.

\section{The Flow of Private Direct Investment to Developing Countries}

The international mineral industry's collective anorexia falls particularly heavily on the developing countries. With a few exceptions, such as Chile, these countries lack a deep and broad based mining tradition, and their infrastructure may be rudimentary. The apparent fragility of their economies and political systems deters all but the most resolute investor.

In most minerals, there is a large inventory of ore deposits discovered in the post war decades. Many are in developing countries, who may believe that they have potentially remunerative assets. Most were, however, found when cost structures were markedly different, and when demand was growing rapidly. Today the large majority of undeveloped ore bodies do not contain reserves which are likely to be economic in the foreseeable future. Attention is normally concentrated solely on the grade and size of deposits rather than on the implied costs, including taxation and financing charges of any product in the market place. Yet the latter is the crucial test of viability made by international companies.

With the withdrawal of most oil companies and the hesitancy of banks and other financial institutions, the international mining companies are one of the few remaining potential sources of finance and know how for those countries which lack established mining expertise. The last few years' experiences have demonstrated all too clearly the relative scarcity of effective talent in all aspects of mine development and operation. They have brought out the need for firm, coherent, and well targeted management, if mines are to remain competitive. Such management is most likely to be provided by organisations which have a strong financial interest in a project's long term profitability.

Where new ore deposits are clearly viable in the terms stated earlier, a competent mining company can usually be found that will be interested in their development. By their very nature, however, such projects are relatively rare in today's oversupplied markets (as are competent companies). Those countries which have mineral resources have to go out and woo potential investors rather than expect a flood of eager suitors. The most effective enticements are a stable and assured legal, institutional and fiscal framework, and the prospect of earning and remitting attractive profits in the resources deployed.

In summary, all countries will be affected by the continuing oversupply of minerals. Those countries with well established domestic mining enterprises, such as Brazil and Chile, will be able to develop new ore bodies, even without the assistance of international mining companies. They would be ill advised to do so, however, unless the prospective ventures appeared not just competitive internationally but relatively low cost. The international mining companies have collectively remained interested in investing in a limited range of minerals, and notably in gold, but even this now faces potentially weak markets in which relative competitiveness counts. There will always be exceptions and special situations but other mining and mineral processing projects stand relatively little chance of attracting foreign interest, unless they are prospectively low cost. As a rule, foreign companies are interested not in mining products for the limited domestic markets of developing countries but for exports.

The mining companies' caution will persist for several more years until excess capacity is squeezed out, and prices resume a healthier relationship with marginal costs. Few developing countries will be able to count on direct foreign investment in their mineral resources until well into the 1990 s. Given the relative inertia of mineral markets, it is quite possible that today's lack of investment will then precipitate shortages and high prices. At present very few mining companies are prepared to treat that as worthy of consideration; in the long run, after all, we are all dead. Survival today is more highly regarded by the mining industry than possible prosperity in the life hereafter. 